\title{
Blurred Visions: Reflecting Visual Anthropology
}

Link to publication record in Manchester Research Explorer

\section{Citation for published version (APA):}

Cox, R., Wright, C., Fardon, R. (Ed.), \& Gledhill, J. (Ed.) (2012). Blurred Visions: Reflecting Visual Anthropology. In The SAGE Handbook of Social Anthropology (Vol. 2, pp. 116-129). Sage Publications Ltd.

\section{Published in:}

The SAGE Handbook of Social Anthropology

\section{Citing this paper}

Please note that where the full-text provided on Manchester Research Explorer is the Author Accepted Manuscript or Proof version this may differ from the final Published version. If citing, it is advised that you check and use the publisher's definitive version.

\section{General rights}

Copyright and moral rights for the publications made accessible in the Research Explorer are retained by the authors and/or other copyright owners and it is a condition of accessing publications that users recognise and abide by the legal requirements associated with these rights.

\section{Takedown policy}

If you believe that this document breaches copyright please refer to the University of Manchester's Takedown Procedures [http://man.ac.uk/04Y6Bo] or contact uml.scholarlycommunications@manchester.ac.uk providing relevant details, so we can investigate your claim.

\section{OPEN ACCESS}




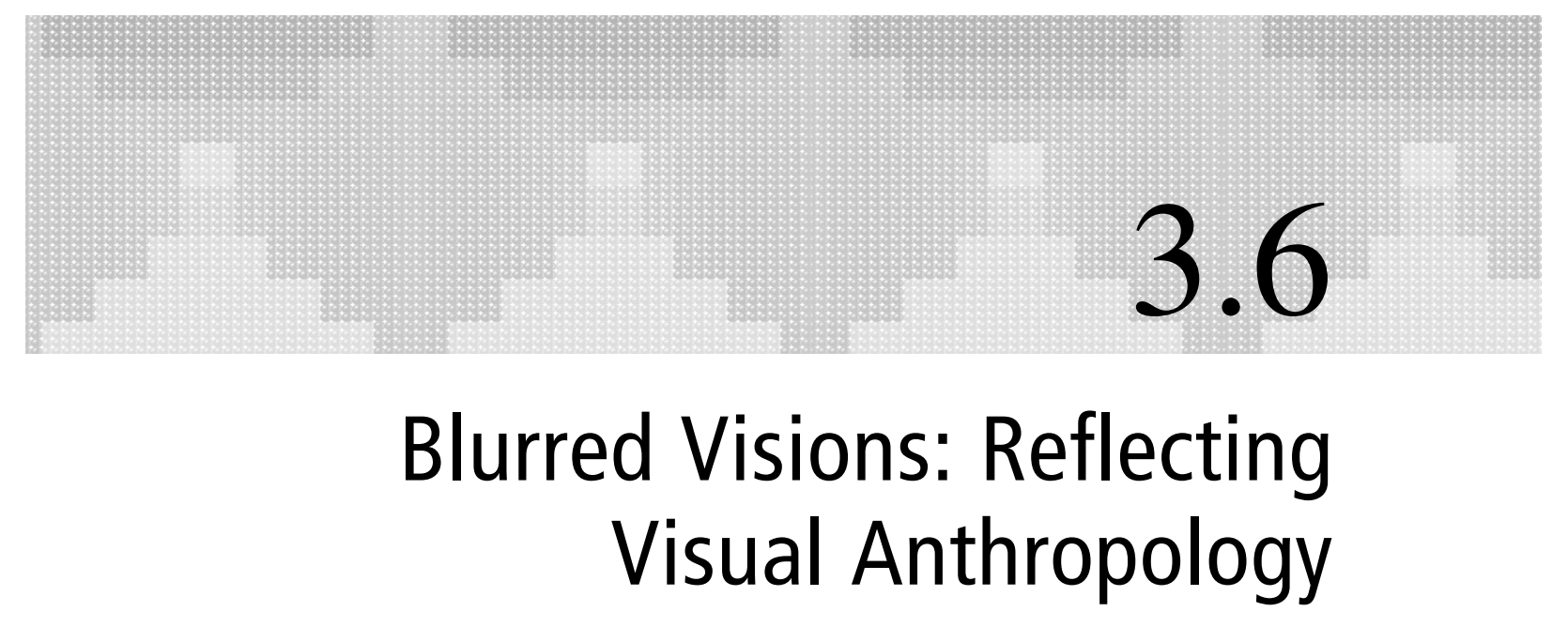

\author{
Rupert Cox and Christopher Wright
}

\section{THE VISUAL FIELD}

In 2001, the American Anthropological Association (AAA) set out guidelines for an evaluation of the field of visual anthropology in terms of its contribution to ethnographic knowledge, its methods and theory, its importance as a form of pedagogy, and its application in anthropological research. The short statement of less than 1,000 words was produced by the Society for Visual Anthropology to address the need for clarification about the qualitative assessment of visual works in terms of disciplinary standards The AAA reached the opinion that visual media are appropriate for the production and dissemination of anthropological knowledge because they can 'convey distinct forms of knowledge that writing cannot' and they provide a means to experience and understand 'ethnographic complexity richness and depth'. Methods of visual media production are equivalent to other ethnographic research techniques in the senses that they include long-term localized engagements, interviews and participant observation. The impact of theory may be less immediately evident in some visual media than in print, but works such as ethnographic films are nonetheless based on and directed towards theoretical analysis. Technical decisions made in production, such as the choices of camera, image composition and the combination of image and sound and image and text, are in themselves all modes of analysis. Hence, visual media 'intrinsically align theory and documentation in the tradition of print scholarship'. The effectiveness of visual media in anthropological pedagogy is asserted, and a claim made that visual anthropology provides a means to engage in anthropology which is for 'made with and/or for the benefit of a particular community, government or business'. In summary, the AAA statement contends that visual anthropology is a form of anthropological research because it is ethnographically descriptive, methodologically committed to participant observation and interviews, theoretically insightful, pedagogically useful and has potential application. The statement is significant because it reflects how longstanding concerns about the relationship with anthropology from within the field of visual anthropology are shared by the AAA, which acts as the largest public representation and governing body of the discipline.

\section{THE CONCEPT}

The AAA statement successfully identifies the centrality of method to the definition of visual anthropology, but it is less clear about the concept of 'the visual' in visual anthropology which is required to define the range of topics, theoretical issues and modes of practice involved. We begin by addressing the question left unposed: What should we understand by the 'visual' in 'visual anthropology'? Questions about the relevance of the visual to anthropological theory and ethnographic practice, whether as concept, subject or method, have foundered on its contrary significations. On the one hand, the visual refers to a world made visible through an underlying scientism 
and Cartesian metaphysic (Benjamin 1999; Buck-Morss 1989; Deleuze 1985, 1994; Jay 1988) and, on the other, it means a mode of sensory apperception variously called 'corporeal vision' (MacDougall 2006), 'haptic visuality' (Marks 2000), 'tactile visuality' (Taussig 1993) and 'attention' in observation (Grimshaw and Ravetz 2009). The radical difference between these views reflects less on the identification of a nominal subject - visual culture - than on different ideas about the nature of visual practices: as functionaries of the structure of imaging technology (Tomas 1992; Weiner 1997), as an ethnographic mode involving reflection upon processes of image production (Pink 2001), or as a quality of corporeal engagement with persons, places and events (Grimshaw and Ravetz 2009; Macdougall 2006). In all these cases, appreciation of image productions as ethnography has been made on the basis of their relative distinctiveness from texts, a tendency which has been judged to betray, at best, circumspection about the visual and, at worst, 'iconophobia' (Taylor 1996). This notion may be extreme but it is still important to understanding debates about the relevance of visual anthropology to the discipline at large, which is the focus of the second half of this essay. Exemplary cases of iconophobia would be Hastrup's epistemological argument (1992) for the 'thickness' of textual narratives in contrast to the map-like, schematic 'thinness' of imagebased description, discussed later in this essay, or Fabian's assertion of an anthropological dependency on static visualism (1983) in contrast to an active vision (Okely 2001). The distinction between these terms is explained by Okely as follows: 'Fabian's definition of visualism selects only one aspect of vision, confining it to the perspective of the surveyor and the draftsman. There are other visions, other ways of seeing, and ones which can be considered experiential rather than detached and omniscient' (2001: 102). One response to iconophobia has taken the form of assertions about the potential of film as ethnography supported by invocation of a canon of works by figures such as Robert Flaherty, John Marshall, Robert Gardner, Timothy Asch and most notably Jean Rouch. In debates about the proper qualification of an 'ethnographic filmmaker' (Ruby 2000), text has been acknowledged as providing necessary contextualization of film, but the potential of alternative ideas have been less thoroughly explored, among these the 'imagetext' (Mitchell 1994), metaphor (Jackson 1983) and montage (Marcus 2008). These alternatives point towards some constructive and evocative conjunctions of text and image on the page. The 'new media', such as 'hyper-media' (Pink et al. 2004), provide examples of such conjunctions, but they are usually supported as 'technical and methodological' means to overcome the disciplinary definition provided by the AAA statement and others like it, rather than as constructive applications of a media 'co-aesthetic' able to provide ethnographic insight in terms particular to the subject under study.

Sensitivity to the representational politics of knowledge production has informed concern for the positioning and responsibilities of the observer relative to the observed, and this dovetails with anthropological debates about the production of indigenous media. In an interesting exchange on the question of whether indigenous films really are modelled by the particular, visual modalities of their cultures, James Weiner (1997), Faye Ginsburg (1991, 1995) and Terence Turner (1991, 1992) debated the capacity of visual media to be defined by their use rather than by their origins. This argument about use has been extended through the work of Sarah Pink (2001, 2004), who has written extensively on how the application of visual methods, ideally in collaboration with subjects, enables researchers to become reflexively aware of the process of ethnographic research and therefore of their ethical, political and indeed sensory roles in creating research outcomes.

The ethnographic utility of this approach is literally 'self'-evident and suggests that a fundamental question for anthropology about visual media concerns the positioning of the researcher and subject seen as a process. This approach, which locates ethnographic authority in the positioning process, further suggests that there may be something to learn from the kind of question which has so invigorated visual studies: namely, 'What do Pictures Really Want?' (Mitchell 1996); i.e. What competences do they require of us in our disciplinary orientations such that we can recognize and respect their particular kind of agency, rather than regarding them merely as a function of a given technology or context?

In what has become known as 'media anthropology', the ascription of degrees of technological and/or contextual determination to media use as part of the politics of indigeneity and other forms of identity construction has made it difficult to separate out what is meant by 'the visual' and how it might be distinguished from visuality, the visible, and vision. In working out these distinctions, it is insightful to refer to the argument of Corsin-Jimenez and Willerslev (2007 concerning the tendency towards holism and stability inherent in 'the anthropological concept of the concept', and the associated inability to find space for what may appear ambiguous and discrepant. In this context, the concept of the visual is anthropologically meaningful in that what is made 
visible through the applications and mechanical operations of the camera is integrative and coherent when it links operator, subject and medium to each other and ideally to anthropological theory. The importance of these links for the concept of the visual is the particular consequence of the observational method of filmmaking with its long takes created from positions of relational familiarity, which appear to allow life to unfold visually as it happens and thus lends itself to this holistic logic. The stability of the concept is directly related to the visual qualities of observational film, with its absence of rapid camera movements, dramatic cuts and angles, because these would alter the understanding that what we are seeing is the viewpoint of an emplaced human observer. All social worlds become potentially visible in the same manner, given this way of operating the camera and its technical capacities for observation.

This is not to argue that there is a naïve technological determinism at the basis of anthropological filmmaking but rather to recognize that there is a 'hermeneutic generosity' (CorsinJimenez and Willerslev 2007: 527) in its signifying concepts which may disregard what is ambiguous or incoherent as an element of the visible made visual. An example of this is the use of blurred images, which lack the clarity and detail we might expect to be necessary in an image with ethnographic value. Later in this essay we consider the juxtaposition of a blurred image and a clear image in the ethnography Sound and Sentiment by Steven Feld, but it is instructive to look first at the case of the Magnum photographer Susan Meiselas. After completing a degree in anthropology at Sarah Lawrence College, Meiselas carried out a photographic project over three years (1972-1975), documenting the lives of Carnival Strippers (2003) in New England, Pennsylvania and South Carolina. Most of the photographs are of a sexual nature, but they are not graphically explicit because they employ camera blur and, in so doing, evoke the emotion of the encounters and reveal the sensitivity of the relationships Meiselas formed with her subjects. This is not a simple strategy, because there are a number of ways of interpreting camera blur, and it is this ambiguity which is indeed its force in this case, for it makes a virtue out of the idea that the visual is never simply identical with the visible, or indeed with vision, and therefore works ethnographically because it constructs a particular form of description that brings together the situation of Carnival Strippers with the capacities of the camera.

The conception of the visual that lies behind this approach to image production draws on the notion that there may be dormant effects of the subject of an image which are manifested through the illusion of presence rather than its direct illustration. MacDougall argues (2006: 57), following Gilberto Perez, that this is film's 'Material Ghost', the capacity to make a direct simultaneous appeal to the senses. It is also part of what CorsinJimenez and Willerslev call a movement of the 'spirit' or following Deleuze, a 'flying' (survol) singularity (1994: 20), meaning the way that an image may be formed of an assemblage or folding together of previously associated but now inactive qualities of the presence of the subject before the camera lens.

Recognition of this fundamentally relational and potentially sensorial aspect of the concept of the visual has the consequence that arguments for reflexive de-positionings of the observer and their methods - in order to expose the artifice of the image and to demonstrate necessary ethical and political sensitivities - are not in themselves sufficient to reveal the ambiguous nature of the visual. This conception also changes the ethnographic value ascribed to styles of filmmaking, which privileged the observationally holistic over the kinds of impressionism which is evident in Meiselas' work and in the fragmentation of constructivism which is evident in the work of surrealist and avante garde filmmakers. It therefore admits a greater corpus of works for consideration, such as those discussed through notions of allegory under the banner of 'experimental ethnography' by Russell (1999).

\section{THE LANGUAGE OF VISUALITY}

The ambiguity of the visual that is at issue here is different in kind (although connected contextually) to the kind of ambiguity discussed by Berger in Ways of Seeing (1990, originally 1972), whereby vision - changes in how we see - are related to what there is to see - the visible. Berger's ideas speak to anthropological concerns for the contingency of visuality on specific cultural conditions and also to the 'rise of the figural' (Lash 1985) whereby contemporary uncertainties in ways of seeing are related to the 'frenzy of the visible' world that surrounds and pervades all our lives (Williams 1999).The appreciation and value of this visual uncertainty is considered in a recent work, The Aesthetics of Uncertainty (2008), by the art historian Janet Wolff, who describes how it is part of a turn to 'imagistic thinking' in sociology with the rejection of the apparently more solid and systematic model of the monograph and the scholarly text (2008: 133-1-34). Imagistic thinking refers to modes of description that pay attention to minute detail, the fragment or 
snapshot, in order to shed light impressionistically, on a broader social scene. It draws heavily on the work of Georg Simmel, Walter Benjamin, Siegfried Kracauer, Ernest Bloch and others.

The language of visuality - Simmel's 'snapshot' (momentbild), Benjamin's 'thought-image' (Denkbild), 'dialectical image' and 'optical unconscious', Ernest Bloch's 'traces' - pervades this imagistic thinking, and while it does not deal with actual images, Wolff argues (2008: 121-122) that we can envisage an imagistic anthropology/ sociology that extends this language to work with actual images. Potentially, this would be a form of descriptive practice that incorporates the opaque open-endedness of the verbal snapshot with the literal snapshot. It is an approach well represented by the conjunction of photographs and text in Kathleen Stewart's ethnography $A$ Space on the Side of the Road (1996). In this work, Stewart merges deliberately the doubtful, uncertain and open-ended nature of life and language in the West Virginia coal camps and 'hollers', hollows or small valleys, that she describes textually with the visual ambiguity of the photographs that she artfully deploys throughout the book. The ambiguity of the photographs lies in the juxtaposition and poetic tension with the narratives of memory and ruin that she writes about, so that the photographs describe through what they do not - as much as what they do - show.

When the relationship between image and text, and between the visible and the visual, is not construed as illustrative and determinative, as in Stewart's work, the practice of thinking in images through forms of writing and thinking with images through forms of media practice can attract charges of impressionism. For these methods are apparently unable to demonstrate the underlying structures of social life with any certainty. Instead, they may claim the virtue of reflecting the uncertainty that is part of the 'ordinary affects' (Stewart 2007) of everyday life, while at the same time employing images that are not simply the presentation of a nominal subject, but an assemblage of qualities that may act as a kind of word-image or line-making. In this sense, they may constitute what the artist, geographer and cultural historian Paul Carter calls 'dark writing':

Dark writing indicates the swarm of possibilities that had to be left out when this line was taken (rather than that line). It notates reflections.... The assembly of shadows, the organization of optical phenomena that resist light, the look of things that suggest a face, the depth of bodies that cannot be unconcealed - all of these fall under dark writing's jurisdiction. (Carter 2008: 1)
Carter's merging of geography, art-history and design as a means of 'material thinking' is productive in suggesting that the conceptual ambiguity of 'visual anthropology' is neither a necessary barrier to working with images, nor to anthropological concerns for analytical writing. His thesis involves the interdisciplinary identification of different kinds of lines and, as such, resonates with the arguments made by Tim Ingold for a 'graphic anthropology' that proceeds by thinking in terms of lines and their relationship with surfaces (2007). For Ingold, anthropology has a propensity to create, through certain modes of writing and (in the case of visual anthropology) a naïve dependency on technological means, linearization and spatial fixity that reproduce an Enlightenment rationality. The challenge is to create lines that are like human perception and therefore lived, participatory and emergent as and through modes of habitation: for Ingold, it is the act of drawing, which being manual and requiring a direct engagement with the elements, is not essentially a technical act and as such avoids the pitfalls of camera work, which confuses a mechanical operation with phenomenological engagement. In this sense, the concept of the visual in 'visual anthropology' is a confusion of the act of seeing with what the operation of the camera makes visible, thereby reducing our understanding of visual perception to looking at mediated images. This radically phenomenological critique makes an important case for anthropological practices that are responsive to the movements of the elements, in this case light, but it passes over many of the ways in which camera work and drawing share concerns for frame, perspective and contrast as well as how these media cross over and inform each other.

This point, that camera work, like drawing and other art practices, involves a certain engagement with the environment and a learned coordination of the senses, which is continuously negotiated and never simply a determination of the materials and technologies being applied, is made in the context of MacDougall's argument for a particular kind of visual anthropology (2006). MacDougall acknowledges that there are distinctive structures to media technologies such as the camera that have an expressive affinity for particular areas of social experience - topographic, temporal, corporeal and personal - such that the epistemological claims of the camera image are essentially perceptual rather than conceptual: that is, "knowledge which has no propositional status (of generality, of explanation) except the proposition of its own existence' (2006: $5)$. The notion of the body as the agential subject and means in the constitution of this kind of knowledge is dependent on its distribution 
across an interactive network formed by the triangle of camera operator, subject and audience. MacDougall argues for the potential of a simultaneous precipitation of this network, through the engagement of the camera operator with their subject in what Jean Rouch called a 'ciné-trance', and of the audience with what Bazin calls 'that hallucination that is true in its effects' (MacDougall 2006: 57). Ingold's arguments are important here because his insistence on 'following the materials' (2000), rather than taking for granted their distribution in this network of productive relations, draws attention to the processes of image formation. The mixing, interchange, transmutation and leaking of elemental energies - light and air - is a part of the process of image creation which is not about the politics of the positioning of observer and observed mentioned earlier, but involves a reformulation of the concept and method of the visual as a relational enfolding or entanglement of the elements.

There are important questions raised by this critique of vision and it will be an interesting direction for future research to consider areas such as the connections between advances in neuroscience and contemporary art practices that Barbara Maria Stafford discusses in her recent work Echo Objects (2007). There are also questions about visual skill (e.g. How is it learned and performed?) which have been addressed in a number of recent works (Grasseni 2004; Grimshaw and Ravetz 2009). They show how skilled vision is both participatory in its responsive engagement with the particularities of any field site, and observational in its commitment to a relational aesthetics. These qualities resonate with issues creatively tackled in Feld's notion of a co-aesthetic which we discuss in the next section. Grasseni's elucidation of the productive affinities between ways of seeing among Italian dairy herders and the ways in which the capacities of the camera can be utilized demonstrates how visual skill is as much about seeing what is there to be described as it is a matter of technical competence in achieving that description. It reveals a quality of 'attention' (Grimshaw and Ravetz 2009) in observation that may be learned and is prior and necessary to the successful application of the camera in the observational film method. The concept which they draw upon in underpinning this notion of skilled vision, and therefore what is visual in visual anthropology, is mimesis, as interpreted by Taussig in Mimesis and Alterity (1993).

For Taussig, following Frazer and Benjamin, mimesis is both a natural capacity and a construction of colonial modernity, achieving its effects through the intersection of ideas about the primitive with the magical powers of 'copy' and 'contact' attributed to the imitative capacities of mechanisms like the camera. The magic of copy and of contact in this notion of mimesis is transformative, turning the ambiguous relationship of vision with the visible and the visual into a generative process that is both simulative and creative, such that every copy contains within it traces of, and the potential for, contact. As an act that does not separate out or privilege vision as discrete from the other senses, mimesis and the copies that result from it engage with the whole sensorium, becoming 'tactile vision' (Taussig 1993). As part of a 'sensuous scholarship' (Stoller 1997), this concept of tactile vision indicates that the visual in visual anthropology can be discussed in terms of the performativity of a variety of media, not simply those which are premised on vision or designed for the production of images. This mimetic performativity of media is demonstrated in the next section through an early example of sensuous scholarship that encapsulates in detail how the dilemmas and productive challenges we have been describing remain vital for contemporary visual anthropology.

\section{ILLUSTRATION AND EVOCATION}

The example is two photographs taken by the anthropologist Steven Feld during his fieldwork among the Kaluli people of Papua New Guinea in the 1970s (Figures 3.6.1 and 3.6.2). Seen in mimetic juxtaposition - which is precisely Feld's intention in reproducing them in his landmark ethnography Sound and Sentiment (Feld 1990) the two images present a theoretical argument through visual form.

The first photograph (Figure 3.6.1) would not seem out of place as an illustration in any anthropological book - it fulfils certain expectations of visual anthropology and relies on a particular model of realism - itself a product of particular European visual traditions. However, the other photograph (Figure 3.6.2) - a blurred image that deliberately obscures its legible content requires something more of its viewer and raises some questions. At first glance it seems less directly illustrative - although this is in some senses misleading based as it is on reading the image - and more evocative, a term that has both positive and negative connotations within anthropology. It might raise questions about whether an image as 'information' or 'data' can, or should, be evocative. Are information and evocation mutually exclusive terms within the field? Is the aim of visual anthropology the presentation of more complete, detailed data, or is it 


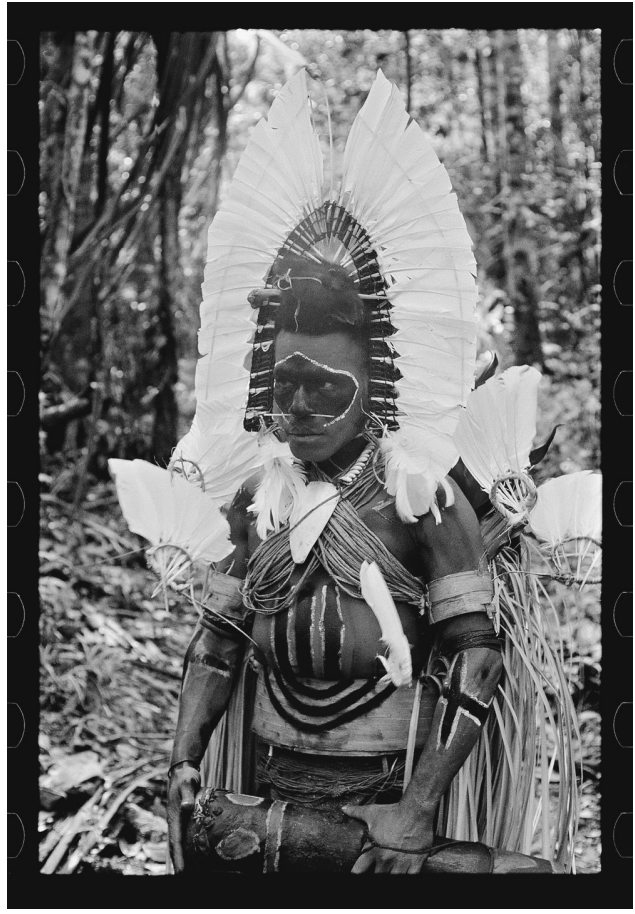

Figure 3.6.1 Gaso of Bon $\supset$ dressed in kJluba costume (from Feld 1990). Image reproduced courtesy of Steve Feld.

evocative representation, or is this in itself a false choice? This blurred photograph performs an aspect of what, following Taussig's thesis about the affective or 'sticky' qualities of the photograph as copy (1993), may be construed as a form of primitive-modern 'magic'. It borrows qualities of the thing that it mimics because it was present before the camera rather than on the basis of verisimilitude or likeness. It involves a form of animation, and it is animation - the work the image does, not simply as a manufacturer of indexical signs but in moving the imagination - that is important, since it raises perennial concerns with the equivalence of the camera's operation to the act of perception. In using a blurred image in this way, Feld stresses the need to be concerned with understanding experience, rather than reducing aesthetics to function and structure (Feld 1990: 233).

The second photograph (Figure 3.6.2) is also concerned with understanding 'the visual', but in a way that is more broadly conceived and that conjoins visual anthropology with the anthropology of art and with the study of other representational systems. This is a familiar tripartite division - the first formalized attempt to define visual anthropology as a sub-field, Paul Hockings' Principles of Visual Anthropology, in 1975, argued that the field consisted of three main areas. These areas were the production of visual material through anthropological fieldwork, the study of other visual systems and the study of what was then referred to as 'non-verbal communication' and covered areas such as proxemics (the study of, particularly inter-personal, spatial distances). The fusion of these strands is a central ethos, and indeed an ethical stance that Feld takes in his fieldwork methods, which are characterized by creative and productive dialogues between different media and between subjects and observers as collaborators. Importantly, Feld sees the work - which itself takes many formats (written, visual and, particularly, aural) - that is produced as a result of fieldwork as the outcome of an encounter between two representational systems (see also Feld 2006). Although the same can be said of the ways in which language, as both speech and text, is often used in anthropology, it is still relatively unusual to find visual anthropologists conceiving of their practice as a kind of hybrid formed from the encounter between two systems, as opposed to adherence to a documentary format of one kind or another. This in-between or ambiguous status of 'the visual' certainly complicates many of the epistemological issues involved, but it does so in a positive and productive way that suggests a whole range of possibilities that should be, and in some cases are, being explored within contemporary visual anthropology. The work of Juan Orrantia, which is concerned with discerning the traces of acts of violence, perpetrated by paramilitaries, in the daily lives of villagers in northern Colombia is one example of contemporary experimental visual anthropology that creatively explores this ambiguous quality. As both process and product, the visual allows Orrantia to access this domain of memory and everyday experience. Combining still photography with sound and also with digital video, he works collaboratively with villagers to represent these traces - the way the past erupts in the present (Orrantia 2009). Similarly, Andrew Irving works with HIV/AIDS patients in Uganda, facilitating their own documentation of their personal stories of the condition through photography and sound to produce works that are not only extremely powerful and resonant but also collaborative in many different ways (2007).

The second photograph (Figure 3.6.2) concerns a central tenet of Kaluli aesthetic and religious systems - the transformation of men into birds. Feld vividly describes dancers entering the longhouse in their costumes by firelight after long 


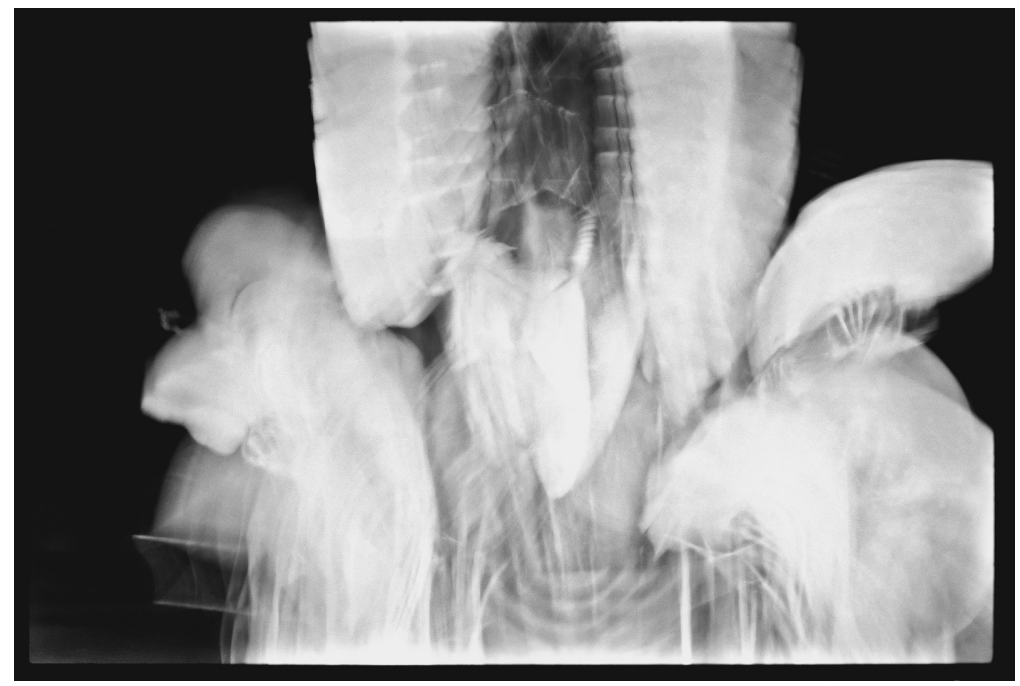

Figure 3.6.2 Dancer seen as 'a man in the form of a bird' (from Feld 1990). Image reproduced courtesy of Steve Feld.

hours of singing. As they rush in they appear as birds '...the photograph is meant to reveal that in ceremonial dance, a man is seen as a bird' (Feld 1990: 235). For Kaluli there is an interpenetration of worlds - animal/human, visible/ non-visible - and as birds sing or men dance they move from one realm to another. The subtleties of this astonishingly rich ethnography are lost here, but the idea of the movement between different perceptual worlds and the strategy of using the particular capacities of photographic images to represent this movement as an illusion of presence resonates with the ideas of MacDougall, and with Corsin-Jimenez and Willserslev (mentioned earlier). This movement is demonstrated by the juxtaposition of these two photographs that - quoting photography critic Alan Sekula - Feld suggests represent opposite ends of a 'folk' model of photography:

... the misleading but popular form of this opposition is 'art photography' vs. 'documentary photography'. Every photograph tends...towards one of these poles of meaning. The oppositions between these poles are as follows: photographer as seer vs. photographer as witness, photography as expression vs. photography as reportage, theories of imagination (and inner truth) vs. informative value... (Sekula quoted in Feld 1990: 235)

As we have argued above, contemporary visual anthropology is still distracted by these kinds of oppositions and in some senses defined by them.
In this light, Elizabeth Edwards' distinction between art and documentary photography as competing forms of rhetoric is useful in helping us understand why the first photograph is, as Feld suggests, something we might take 'refuge' in, and an image that would not seem misplaced in any monograph, whereas the second presents more of a challenge (Edwards in Banks and Morphy 1997; Feld 1990: 233). Feld's photographs directly illustrate the kinds of oppositional models that are still central to much current discussion within visual anthropology, models that continue to underlie what Lucien Taylor has argued is anthropology's 'iconophobia' (Taylor 1996). These dyadic oppositional models - text vs image, illustration vs evocation, art vs science, realism vs impressionism, expression vs reportage, etc. - continue to dominate much anthropological thinking about visual methodologies and the use of visual images more generally within anthropology. Taylor cites several examples of such anthropological suspicion and open hostility towards the use of images within the discipline. He suggests that in these cases, '[V]isuality itself becomes merely ancillary, illustrative rather than constitutive of anthropological knowledge' (1996: 66). The pervasiveness of these oppositional models, the way in which they have continued to frame debates around visual anthropology, reveals the central status of many of the questions they raise. Some of these oppositions are perhaps no longer productive - and they do not engage with, for example, 
Lyotard's discussion of discourse/figure, or Mitchell's idea of the 'image-text', and so their dominance is, as Sekula suggests, misleading. They have, however, given rise to some of the central, and ongoing, arguments in this sub-field.

One of these arguments, which is central to the definition of visual anthropology by the AAA and has been written about eloquently and convincingly by David MacDougall, is whether visual anthropology is concerned with creating new kinds of anthropological knowledge, or with constructing itself as the visual equivalent of anthropological text (MacDougall 1999, 2006). As we have seen, this question is at the heart of many contemporary criticisms of 'the visual' from within the discipline and particularly indicative of those that disparage media-generated images and film in particular, for not providing the same 'ethnographic qualities' or theorizing potential as a written text (Ruby 2000). The notorious arguments provoked by Robert Gardener's 1986 film Forest of Bliss, about the meaningfulness of the images of the burning ghats (waterside cremation sites) of Benares in India, are still particularly useful for revealing the polarizing effects of these oppositional models. As MacDougall says, "the film tends to divide its critics into those who have a view - of historical reality, or Benares, or India, or anthropology which the film offends and those who, perhaps even despite this, see value in such a radically different kind of film being made' (2001: 69). The film has no subtitling or narrative voiceover and, for its critics, its visual qualities are problematic - for Alexander Moore 'a beautiful visual exercise is just that, an exploration of imagery, not an anthropological document which can be said to illuminate the universal human condition, or to enlighten its audience' (Moore 1988: 2). In relation to this view, Jay Ruby suggests that,

... the chief criteria we should employ in critiquing a film which purports to be somehow 'anthropological' or 'ethnographic' are those of anthropology. Whether it is a 'good' film or an artistic achievement is basically irrelevant. While we need to be competent in our craft, our major concern is not to produce 'good' films any more than it is with producing 'good' books. (Ruby 1989: 9)

In his rebuttal of the way in which the film was treated by some anthropologists, MacDougall argues positively for a visual anthropology that has a different set of concerns and produces new ways of knowing and representing than its textbased counterpart (2001). For him the film represents 'new conceptual possibilities for visual anthropology' and is a prototype: an experiment in a radical anthropological practice which explores the largely invisible interrelations of the visible world through visual (and it must be added, auditory) means ... [and] ... it seeks to do so in a fashion that resembles the way in which sensory awareness, cultural meaning, and metaphorical expression are combined in social experience. (MacDougall 2001: 71)

As well as issues of anthropological knowledge, what is at stake here is an attitude towards 'craft', and such attitudes are central to Tim Ingold's thesis (2007) about drawing as an ethnographic skill and are key towards the way in which experiment (Russell 1999) is valorized, or not, within the discipline. Approaches to craft and experimentation are key issues for the future development of visual anthropology as an aggregation of media practices directed towards social research, but they must contend with long-standing aversions in the discipline that express what Taylor has called 'iconophobia' (1996).

\section{ICONOPHOBIA}

In his influential article, Taylor discusses one particular example that reveals this anti-craft sentiment - Kirsten Hastrup's 1992 essay on 'anthropological visions'. Basing her criticisms of visual anthropology on her own experience of attempting to take photographs that reveal the aura of male sexuality that pervades an Icelandic ram festival that she witnessed, Hastrup argues that the resulting images only showed the surface of events,

... the nature of the event could not be recorded in photography. The texture of the maleness and sex which filled the room had been an intense sensory experience, but it was invisible. The reality of the total social event had been transformed into a two-dimensional image, a souvenir. (1992: 9)

Hastrup denounces photography as a form of 'thin description' that can only show the surface of events, a record of behaviour, rather than the 'thick description' that can be offered by text with its ability to provide an account of meaning, transcend the particular, move back and forth in time, and so on (1992: 10).

Of course film can very easily move back and forth in time - this is one of its defining features as a medium, and photographs can in some ways also transcend the exigencies of the conditions of their making - but what is perhaps more interesting are the presumptions Hastrup makes concerning visual media, visibility and visuality, 
and the usefulness of these concepts within anthropology. It is the craft or methodological aspect of 'the visual' that is a key point of contention here. Hastrup seems to replicate an often-quoted statement by the ethnographic filmmaker Timothy Asch - that the camera is to the anthropologist, as the telescope is to the astronomer, and the microscope to the biologist (Asch et al. 1973; see also Wright 1998) - effectively disavowing issues of craft or technique in favour of the determining characteristics of the technology. Although Asch's considerable body of filmmaking with the anthropologist Napoleon Chagnon is actually far more nuanced than this idea of visual media would suggest, the quote demonstrates the way in which the visual - as technical method and as craft - is often approached in a particularly forensic manner within anthropology, an attitude that has had its critics from the outset (Edwards 2001; Rony 1996). In various different guises, the tensions between treating the camera as a technical recording device, or as a tool for skilled expression, remain a feature of contemporary visual anthropology in both a theoretical sense and in the ways the field goes about reproducing itself.

For a period in the 1970 s and 1980 s, visual anthropology, which was then and in many ways still is, largely seen as synonymous with ethnographic filmmaking, was often treated pedagogically as a process of technical training, teaching already-trained and qualified anthropologists how to use what was then a $16 \mathrm{~mm}$ film camera. However, this technical training also took place in many cases within a framework of some form of observational filmmaking that focused on getting students to develop the skill of paying attention to the world in particular ways. It was explicitly concerned with the texture of the world and with fostering a certain kind of attentiveness in both filmmaker and audience (see Grimshaw and Ravetz 2009, and Saunders 2007 for histories of observational cinema). Although perhaps initially bound up with what, in hindsight, were misplaced notions of technical witnessing, observational cinema is currently enjoying a renaissance both within and outside of anthropology and

the distinctive techniques and aesthetics of observational filmmaking no longer appear as evidence of a simple-minded scientism or old-fashioned ethnographic realism... [but are] ... constitutive of a reflexive praxis, a way of doing anthropology that has the potential to creatively fuse the object and medium of enquiry. (Grimshaw and Ravetz 2009: 136)

There is a continuing ambivalence around the use of visual material within anthropology, but contemporary developments suggest that embrac- ing the expressive and evocative aspects of visual media can lead to representations that combine, as MacDougall suggests, sensory awareness, cultural meaning, and metaphorical expression (MacDougall 2001).

In his critique, Taylor argues that, for Hastrup, 'only writing can evoke the existential texture of the "place" to someone who wasn't there' (Taylor 1996: 67). Her example reveals some of the anxiety that continues to surround visual anthropology's perceived non-textual or antitextual stance and suggests that it is the ability of text to evoke a sense of texture that makes it superior to visual media. This demonstrates the double bind to which visual anthropology is often subjected - it is either too evocative and expressive, exceeding its role as illustration, or it is the opposite: too limited to surface and unable to reveal any depth. The visual is either productive of a surfeit or plenitude of meaning that needs to be constrained by text, or it is devoid of meaning, incapable of the kinds of 'thick description' and texture that text can provide (see Pinney 1992 for a useful counter argument to Hastrup). Such controversies, exemplified by Gardner's film and by Hastrup's discussion of photography, indicate the more general contours of debates around visual anthropology that have dominated recent decades.

Another of the key issues at stake in Hastrup's argument is her own role in taking the photographs. Feld points out, in relation to his blurred photograph (Figure 3.6.2), that it was very much theoretically premeditated and that it forms part of a positive exploration of the possibilities for representation within the particular fieldwork setting in which he was working. The idea that it might be necessary and insightful to plan theoretically or think experimentally about how to take images of the ram festival that do reveal the male sexuality pervading the event, or that such preparation might have required an explicit engagement with genres of photography that have dealt with such events and themes, does not figure in Hastrup's account of anthropological observation. Rather, her argument seems to suggest that it was not necessary for her to plan or construct how she might go about representing male sexuality except by means of the way in which it was made visible to the fundamental technical operation of the camera. It is as if she relies on a conception of her camera as a particular kind of technical recording device and on a certain narrow notion of witnessing and visual realism or literalism Although this is not clearly spelt out by Hastrup, it does seem to be an important assumption underlying the chapter and it seems restrictive considering the vast range of options for image-making that are potentially 
available through different camera technologies and techniques (Weinberger 1992). It is not that any resistance to images and their use is by definition iconophobic, but that the seeming unwillingness to engage with the visual more broadly destines the project to fail.

This is where Feld's example is so productive and prescient: in his willingness to experiment, his use and combination of a wide range of different media (sound, visual, text-based), and in his open acknowledgement of a specifically visual form of co-aesthetic as opposed to some narrow definitions of documentary (Feld 1990, 2006). Feld anticipates the current shift in visual anthropology towards methodological explorations that combine the call for attention to the specificities of particular media (as in Taylor 1996; MacDougall 2006; Grinshaw and Ravetz 2009), alongside an ethical concern for the development of a co-aesthetic. The latter has recently seen increased attention through considerations of the work of Jean Rouch that explore his notion of a shared anthropology, and Henley's important recent study takes this co-aesthetic as a way of thinking through the actual practice of Rouch's filmmaking (Feld 2003; Henley 2010). Feld demonstrates the radical potential for visual anthropology to be concerned with the encounter between - perhaps the literal interpenetration of - different systems of perception and representation. In other words, with the ways in which the images are produced by Feld and the Kaluli, how they circulate between them, how they comment on each other, lead to further images, etc. His decision to 'use a metaphoric convention from my own culture's expressive tradition in photography to make a synthetic and analytic statement about a Kaluli metaphor', and his insistence that it is 'the imaging code typically considered to be the least documentary and the most "artistic" [that] structures what is the most ethnographic of my photographs', both point to the theoretical and practical creativity of his methodologies (Feld 1990: 236).

Like Marilyn Strathern's creative comparison of one of her own photographic portraits of a Hagen man from the Highlands of Papua New Guinea donning his dance costume with a genetic fingerprint and its 'barcode' of identity (1997), Feld's images raise questions about the medium of photography itself. There is a sense in which both of Feld's images, in technical terms, have equal value as 'documents'. The notion of 'document', as it is often applied within visual anthropology, does not always account for its broad history and application, for example as a radical form of surrealism by Georges Bataille, in his short-lived magazine of that name (Ades et al. 2006), and in relation to surrealist photography (Krauss 1985).
Questions of photography's identity as a medium are useful to consider in the light of Hastrup's comments above, since the latter reveal a certain culturally and historically specific understanding of the medium. The critique of nineteenth-century anthropological and colonial photography that developed in the 1980s has had a profound impact on the development of visual anthropology (Edwards 1992; Poole 2005). But, as Stephen Nugent points out in an important work on the iconography of Amazonia, we do not yet really know enough about the history of the visual in anthropology and its relation to popular images of others (Nugent 2008). It seems strange that anthropologists frequently fail to consider the historical and cultural variables of attitudes towards photography and other media (see Benjamin 1979; Pinney and Peterson 2003). Two studies that do address these issues productively are Christopher Pinney's extremely rich and detailed study of attitudes to photography in central India, Camera Indica (1997), a study of the social life of Indian photographs, and Jennifer Deger's brilliant ethnography of media production in an Australian Aboriginal community, Shimmering Screens (Deger 2006). Both take into account James Weiner's influential consideration of the 'Western metaphysic' of media in relation to the development of indigenous video projects (Weiner 1997), and Deger is also involved in the collaborative production of visual work that explores the qualities of media such as digital video.

Feld's juxtaposition of these two photographs reveals questions about photography's identity as a medium and is productive, provocative and revealing of many contemporary debates about the possibilities for producing and using visual material within anthropology. These debates show no signs of being resolved into anything that resembles a commonly held set of principles - and part of the debate concerns whether or not that is actually desirable in any way. There is much heated debate concerning visual anthropology's coherence, or not, as a separate field (see Taylor 1998). What is usually presented in handbooks of visual anthropology is some version of the history of the field along with a series of methodologies, visual practices and visual tools that, although undoubtedly offering the potential for creativity, do not offer a consensus on the role of 'the visual' and how it may refer to a concept, method and subject. This is perhaps both a weakness and a strength - what to some is an inchoate field lacking in agreed principles and criteria for evaluation, is for others the sign of creative fecundity (Taylor 1998). Despite some early and more recent attempts to establish principles of various kinds (Banks and Morphy 1997; Hockings 
1975; Ruby 2000), visual anthropology remains a subject that is characterized by its relative lack of agreement about methods or concepts, and this should perhaps be seen as a redeeming positive feature of the sub-field, rather than a drawback. Although many, if not all, anthropologists make use of visual material of some kind - in their writing, lectures and web-based endeavours - they do so mostly in terms of illustration, and not as a way of engaging with some of the exciting possibilities raised by considering visual anthropology in the ways we are suggesting here. In marking itself out as a distinctive field, visual anthropology is still, all too often, seen perhaps by default, as defined against that which it is not - as in many ways embattled with text. This is a false opposition, and Feld himself has worked on projects that productively combine text, image and sound, such as the brilliant Bright Balkan Morning (Blau et al. 2002). If this opposition was overcome, perhaps many more anthropologists would be encouraged to experiment with the visual. In an important sense, many of the dilemmas facing contemporary visual anthropology are not necessarily new ones: they have been rehearsed many times, and are perhaps as much to do with the institutional politics of university departments and the viability of a field that consumes time and significant resources in a period of economic austerity. For example, the shortlived 1970s journal Alcheringa - which combined translations of various kinds (paragraphs of LéviStrauss translated into Nambikwara), articles on concrete poetry and examples of ethnopoetics together with a floppy vinyl $45 \mathrm{rpm}$ sound recording - still seems radical in its creative combinations of texts and sounds.

The complex and demanding assembly of technologies and techniques necessary for learning, teaching and experimenting in visual anthropology, which also in some ways define the parameters of the field, also highlights its vulnerability under current conditions where the timely production of peer-reviewed journal articles seems the most important measure of worth and progress. The tools most necessary to visual anthropology, as an extra-textual or non-textual enterprise, are often those in shortest supply - time, opportunity, resources and the need to embrace uncertain or different outcomes. These are necessary to create the sort of work that Feld has produced, suggesting a range of productive methodologies for working with image, sound and text. The structural and disciplinary disparagement of, or at least reluctance to encourage, experimentation has perhaps resulted in an overemphasis on technical training in visual anthropology. There is a world of difference between visual anthropology as technical training in how to use a video camera, versus visual anthropology as an approach to 'the visual' in a more broadly defined sense. Although the two are not mutually exclusive - indeed, a full technical training could well encourage experimentation - there remains resistance to experimentation at an institutional and disciplinary level, and it is also discouraged by a researchfunding climate that favours predictable outcomes. If this were overcome, visual anthropology would become something that, as Grimshaw and Ravetz argue in relation to the current renaissance of observational filmmaking, is not then about creating an accurate transcription of the world .. [but i] nstead ... hinges upon connection, expressed in an almost intangible, empathic moment' (2009: 136). For MacDougall, visual media allow for a kind of knowledge that is constructed not by description, but by a form of acquaintance (MacDougall in Banks and Morphy 1997: 286); a general consideration of the visual such as this should be as much a part of visual anthropology training as learning to operate a digital video camera.

In a review article of the state of the field, Taylor (1998) argued that visual anthropology 'offers possibilities for anthropology, and in particular for the representation and evocation of lived experience, that are unavailable to writing' (Taylor 1998: 535). Leaving aside any ongoing and unresolved tensions with anthropological text would allow visual anthropology to concentrate on exploring the properties of various media visual and aural - and this in turn could perhaps enable a more positive and creative experimentation with anthropological ways of knowing and representing. Although anthropologists have long wanted to distinguish between a written anthropology that attends to visual culture, and an anthropology conducted through visual media (see Banks and Morphy 1997), and although Taylor suggests that 'the two are still sufficiently unlike one another that it is as well to distinguish between them at the outset' (1998: 534), it is a convergence of the two that would encourage the kinds of methodologies pursued so fruitfully by Feld.

A notion of performativity ties together all the examples and practitioners discussed above and offers a range of productive possibilities. The notion has its roots in the anthropology of ritual, but when applied to media it signals a concern for the experience of viewers and audiences, and this has some very real consequences for contemporary visual anthropologists. Lucien Taylor and Ilisa Barbash's recent film Sweetgrass, which is attracting large audiences on general release in the US cinemas (Taylor 2010), is part of a series of works that evolved from their fieldwork with transhumance sheep-herders in Montana. 
Taylor chose to show one of these works, Sheep Rushes, in the Marion Goodman Gallery in New York alongside work by artists such as Steve McQueen (see Goodman 2007). He felt that the work, designed as a single-screen projection with precise attention to qualities of light and colour, needed a certain level of performativity in its presentation. This attention to performativity has led to some experimental visual anthropologists exploring alternative venues to exhibit their work. The Tate Modern art gallery in London ran a short theoretical and practical course in 'Experimental Ethnography' in 2010, while an innovative group exhibition of work by visual anthropologists and artists, Ethnographic Terminalia, organized by Craig Campbell to coincide with the 2009 AAA conference, was shown in a Philadelphia art gallery (Campbell 2009). That such forward-looking and creative visual anthropology is being shown in these spaces says something about the current concerns of the contemporary art world, but also about the relative lack of such spaces, perhaps both physical and conceptual, within anthropology. It is this, and some of the oppositions that hinder that lack of engagement, that need to be overthrown to enable the productive pursuit of experimental visual methodologies.

\section{REFERENCES}

Ades, Dawn, S. Baker, C. Hancock, D. Hollier, \& C. Miller (2006) Undercover Surrealism: Georges Bataille and Documents. London: Hayward Gallery.

Asch, Timothy, John Marshall, \& Peter Spier (1973) 'Ethnographic film: structure and function', Annual Review of Anthropology 2: 179-187.

Banks, Marcus \& Howard Morphy, eds (1997) Rethinking Visual Anthropology. New Haven, CT: Yale University Press.

Benjamin, Walter (1979) 'A short history of photography'. In One Way Street and Other Writings. London: Verso.

Benjamin, Walter (1999) The Arcades Project, S Buck-Morss (ed.). Cambridge, MA: MIT.

Berger, John (1990, originally 1972) Ways of Seeing. London, British Broadcasting Corporation and Penguin.

Blau, Dick, C. Keil, A. Keil, \& S. Feld (2002) Bright Balkan Morning: Romani Lives and the Power of Music in Greek Macedonia. Middletown, CT: Wesleyan University Press.

Buck-Morss, S. (1989) Dialectics of Seeing: Walter Benjamin and the Arcades Project. Cambridge, MA: MIT Press.

Campbell, Craig (2009) http://www.metafactory.ca/ terminalia/

Carter, Paul (2008) Dark Writing: Geography, Performance, Design. Honolulu: University of Hawaii Press.

Corsin-Jimenez, Alberto \& Rane Willerslev (2007) 'An anthropological concept of the concept: reversibility among the
Siberian Yukaghirs', Journal of the Royal Anthropological Institute (N.S.) 13: 527-544.

Deger, Jennifer (2006) Shimmering Screens: Making Media in an Aboriginal Community. Minneapolis, MN: University of Minnesota Press.

Deleuze, G. (1985) Cinema 2: The Time-Image. Translated by H. Tomlinson, R Galeta. Minneapolis, MN: University of Minnesota Press.

Deleuze, G. (1994, originally 1968) Difference and Repetition. Translated by P. Patton, New York: Columbia University Press.

Edwards, Elizabeth, ed. (1992) Anthropology and Photography, 1860-1920. New Haven, CT: Yale University Press.

Edwards, Elizabeth (2001) Raw Histories: Photographs, Anthropology and Museums. Oxford: Berg.

Fabian, J. (1983) Time and the Other: How Anthropology Makes its Object. New York: Columbia University Press.

Feld, Steven (1990, originally 1982) Sound and Sentiment: Birds, Weeping, Poetics and Song in Kaluli. Expression, 2nd revised edn. Philadelphia, PA: University of Pennsylvania Press.

Feld, Steve, ed. (2003) Ciné-Ethnography: Jean Rouch. Minneapolis, MN: University of Minnesota Press.

Feld, Steven (2006) 'Dialogic editing: interpreting how Kaluli read sound and sentiment'. In A. Robben \& J. Sluka (eds), Ethnographic Fieldwork: An Anthropological Reader. New York: Wiley-Blackwell.

Fabian J. (1983) Time and the Other: How Anthropology Makes its Object. New York: Columbia University Press.

Ginsburg, Faye D. (1991) 'Indigenous media: Faustian contract or global village?' Cultural Anthropology 6 (1): 92-112.

Ginsburg, Faye D. (1995) 'Mediating culture: indigenous media, ethnographic film and the production of identity'. In L Devereaux \& R Hillman (eds), Fields of Vision: Essays in Film Studies, Visual Anthropology and Photography. Berkeley, CA: University of California Press, pp. 256-291.

Goodman, Marian (gallery) (2007) http://www.mariangoodman. com/exhibitions/2007-06-21_equal-that-is-to-the-real-itself/

Grasseni, Cristina (2004) 'Video and ethnographic knowledge: skilled vision in the practice of breeding'. In A.I. Alfonso, L. Kurti \& S. Pink (eds), Working Images: Methods and Media in Ethnographic Research. London: Routledge, pp. 15-30.

Grasseni, Cristina, ed. (2007) Skilled Visions: Between Apprenticeship and Standards. New York: Berghahn Books.

Grimshaw, Anna \& Amanda Ravetz (2009) Observational Cinema: Anthropology, Film and the Exploration of Social Life. Bloomington, IN: Indiana University Press.

Hastrup, Kirsten (1992) 'Anthropological visions: some notes on visual and textual authority'. In P.I Crawford \& D. Turton (eds), Film as Ethnography. Manchester: Manchester University Press.

Henley, Paul (2010) The Adventure of the Real: Jean Rouch and the Craft of Ethnographic Cinema. Chicago, IL: Chicago University Press.

Hockings, Paul (1975) Principles of Visual Anthropology. Berlin: Mouton de Gruyter. (second edition printed 1995). 
Ingold, Tim (2000) The Perception of the Environment: Essays on Livelihood, Dwelling and Skill. London: Routledge.

Ingold, Tim (2007). Lines: A Brief History. London: Routledge. Irving, Andrew (2007) 'Ethnography, art and death', Journal of the Royal Anthropological Institute 13 (1): 185-208.

Jackson, Michael (1983) 'Thinking through the body: an essay on understanding metaphor', Social Analysis 14: 127-149.

Jay, Martin (1988) 'Scopic regimes of modernity'. In ForceFields: Between Intellectual History and Cultural Critique. New York/London: Routledge, pp. 115-133.

Krauss, Rosalind (1985) L'Amour Fou: Photography and Surrealism. New York: Abbeville Press.

Lash, Scott. (1985) 'Discourse or figure? Postmodernism as a 'Regime of Signification', Theory, Culture \& Society 5: 311-336.

MacDougall, David (1999) Transcultural Cinema. Edited and with an introduction by Lucien Taylor. Princeton, NJ: Princeton University Press.

MacDougall, David. (2001) Review of Making Forest of Bliss: Intention, Circumstance and Chance in Nonfiction Film. A Conversation between Robert Gardner and Ákos Östör. Cambridge, Massachusetts and London: Harvard Film Archive, 2001. Visual Anthropology Review 17 (1): 68-85.

MacDougall, David (2006) The Corporeal Image: Film, Ethnography and the Senses. Princeton, NJ: Princeton University Press.

Marcus George (2008) 'The modernist sensibility in recent ethnographic writing and the cinematic metaphor of montage', Visual Anthropology Review 6 (1): 2-12.

Marks, Laura U. (2000) The Skin of Film: Intercultural Cinema, Embodiment and the Senses. Durham, NC: Duke University Press.

Meiselas, Susan (2003) [1976] Carnival Strippers. New York: Whitney Museum of American Art; Göttingen, Germany: Steidl Publishers.

Mitchell, W.J.T. (1996) 'What do pictures really want?' October 77: 71-82.

Mitchell, W.J.T. (1994) Picture Theory: Essays on Verbal and Visual Representation. Chicago, IL: University Chicago Press.

Moore, Alexander (1988) 'The limitations of imagist documentary: a review of Robert Gardner's Forest of Bliss', Society for Visual Anthropology Newsletter 4 (2): 1-2.

Nugent, Stephen (2008) Scoping the Amazon: Image, Icon, Ethnography. Walnut Creek, CA: Left Coast Press.

Okely, Judith (2001) 'Visualism and landscape: looking and seeing in Normandy', Ethnos 66: 99-120.

Orrantia, Juan (2009) http://www.documentography.com/ issue/11/ph/Juan/1.htm

Pink, Sarah (2001) Doing Visual Ethnography, Images Media and Representation in Research. London: Sage Publications.

Pink, Sarah, László Kürti, \& Ana Isabel Afonso, eds (2004) Working Images, Visual Research and Representation in Ethnography. London: Routledge.
Pinney, Christopher (1992) 'The lexical spaces of eye-spy'. In P.I Crawford \& D. Turton (eds), Film as Ethnography. Manchester: Manchester University Press.

Pinney, Christopher (1997) Camera Indica: the Social Life of Indian Photographs. London: Reaktion.

Pinney, C \& N. Peterson, eds (2003) Photography's Other Histories. Durham, NC: Duke University Press.

Poole, Deborah (2005) 'An excess of description: ethnography, race, and visual technologies', Annual Review of Anthropology 34: 159-79

Rony, Fatimah T. (1996) The Third Eye: Race, Cinema, and Ethnographic Spectacle. Durham, NC: Duke University Press.

Ruby, Jay (1989) 'The emperor and his clothes: a comment', Society for Visual Anthropology Newsletter 5 (1): 9-11.

Ruby, Jay (2000) Picturing Culture: Explorations of Film and Anthropology. Chicago: University of Chicago Press

Russell, Catherine (1999) Experimental Ethnography: The Work of Film in the Age of Video. Durham, NC: Duke University Press.

Saunders, Dave (2007) Direct Cinema: Observational Documentary and the Politics of the Sixties. London: Wallflower Press.

Society for Visual Anthropology (2001) Guidelines for the Evaluation of Visual Media. Arlington, VA: American Anthropological Association.

Stafford, B.M. (2007) Echo Objects: The Cognitive Work of Objects. Chicago, IL: University of Chicago Press.

Stewart, Kathleen (1996) A Space on the Side of the Road: Cultural Poetics in an "Other" America. Princeton, NJ: Princeton University Press.

Stewart, Kathleen (2007) Ordinary Affects. Durham, NC: Duke University Press.

Stoller, Paul (1997) Sensuous Scholarship. Philadelphia, PA: University of Pennsylvania Press.

Strathern, Marilyn (1997) 'Pre-figured features: a view from the Papua New Guinea Highlands'. In Joanna Woodall (ed.), Portraiture: Facing the Subject. Manchester: Manchester University Press.

Taussig, Michael (1993) Mimesis and Alterity: A Particular History of the Senses. New York/London: Routledge.

Taylor, Lucien (1996) 'Iconophobia,' Transition 69: 64-88.

Taylor, Lucien (1998) 'Reviewed work(s): Rethinking Visual Anthropology by Marcus Banks, Howard Morphy (eds.); Principles of Visual Anthropology by Paul Hockings (ed.); Fields of Vision: Essays in Film Studies, Visual Anthropology, and Photography by Leslie Devereaux, Roger Hillman (eds.), American Anthropologist, New Series, 100 (2): 534-537.

Taylor, Lucien (2010) http://sweetgrassthemovie.com/

Tomas, David (1992) 'Manufacturing vision: Kino-Eye, the man with a movie camera, and the perceptual reconstruction of social identity', Visual Anthropology Review 8 (2): 27-38.

Turner, Terence (1991) 'The social dynamics of video media in an indigenous society: the cultural meaning and personal 
politics of video-making in Kayap'o communities', Visual Anthropology Review 7 (2): 68-72.

Turner Terence (1992) 'Defiant images: the Kayap'o appropriation of video', Anthropology Today 8 (6) 5-16.

Weinberger, Elliot (1992) 'The camera people', Transition 55: 24-54.

Weiner James F. (1997) 'Televisualist anthropology: representation, aesthetics, politics', Current Anthropology 38 (2): 197-235.
Williams, Linda (1999) 'Prehistory: the frenzy of the visible.' In Hard Core: Power, Pleasure and the 'Frenzy of the Visible'. Berkeley, CA: University of California Press, pp. 34-57.

Wolff, Janet (2008) The Aesthetics of Uncertainty. New York: Columbia University Press.

Wright, Christopher (1998) 'The Third Subject: perspectives on visual anthropology', Anthropology Today 14 (4). 